\title{
Fetal lung compliance in premature and term lambs after two methods of in utero repair of diaphragmatic hernia
}

\author{
David W Parsons, W D Andrew Ford, Johanna C Cool, A James Martin, \\ Rima E M Staugas, J Declan Kennedy
}

\begin{abstract}
Background - In utero surgery was used to correct a surgically induced model of congenital diaphragmatic hernia (CDH) in premature and term lambs, resulting in an improvement in lung mechanics at birth.

Methods - The differences between the in utero "patch" repair method and the "silo" repair method were assessed in 55 lambs by measuring the static respiratory system compliance (CST,RS) at birth in term (approximately 145 day) and in premature (128 day) animals.

Results - Both methods resulted in similar improvements in CST,RS in term lambs, but in premature lambs only the silo method produced an increase in compliance. Comparisons of specific compliance related to length or birth weight did not alter these findings; however, corrections related to lung weight or a measure of lung volume showed there was no difference between any experimental groups in either term or premature lambs.

Conclusions - These findings suggest that there was no difference in the intrinsic compliance of the lung tissue between normal, unrepaired and repaired animals, and that the differences in respiratory system compliance measured at birth may be due primarily to differences in lung size. The silo repair method appears to provide an earlier improvement in CST,RS than the patch repair method.
\end{abstract}

Department of Pulmonary Medicine D W Parsons

A J Martin

R E M Staugas

J D Kennedy

Department of Paediatric Surgery W D A Ford J C Cool

Women's and Children's Hospital (Adelaide Children's Hospital Campus),

North Adelaide,

South Australia 5006

Reprint requests to: Dr D W Parsons.

Received 7 March 1994 Returned to authors

6 May 1994

Revised version received

26 May 1994.

Accepted for publication

31 May 1994 improves outcome, ${ }^{5-7}$ not all infants benefit from postnatal surgery. In some cases compliance deteriorates after surgery, interfering with respiratory efforts, ${ }^{5}$ while in others compression of both ipsilateral and contralateral duced such severe pulmonary hypoplasia that death is inevitable.

In an attempt to improve the poor prognosis of infants born with $\mathrm{CDH}$, surgical intervention in utero has been advocated. Harrison et al $l^{8}$ described one method for in utero repair of $\mathrm{CDH}$ using a flat Goretex patch which is sutured into the defect following reduction of the herniated viscera. However, this method has several disadvantages. Firstly, abdominal pressure rises due to the volume of the viscera returned to the abdomen, requiring the creation of an abdominal wall defect to maintain normal abdominal pressure; ${ }^{8}$ this additional surgery increases the complexity of the fetal repair procedure. Secondly, growth of the repaired diaphragm may be impaired by the fixed area of the patch. Thirdly, the patch technique is unsuitable in those cases with herniated liver in the chest since retraction of liver into the abdomen may kink and obstruct the ductus venosus and lead to fetal death. The liver is in the chest in approximately $50 \%$ of cases of $\mathrm{CDH}$ that are diagnosed in utero, ${ }^{8-10}$ and it has been reported that this group will have a $90 \%$ mortality at birth when there is no antenatal intervention. ${ }^{310}$ Finally, after in utero surgery in human fetuses uncontrollable premature labour often occurs, ${ }^{4}$ so the method to be used should have the best chance of improving lung compliance quickly.

A different technique, using a more gradual reduction of the viscera over several weeks of fetal development, might allow for repair without acute ductal kinking and improve the survival in this group with liver herniated into the chest. Thus, an alternative "silo" method of in utero correction of diaphragmatic hernia has been developed. ${ }^{112}$ This method involves the wrapping of a Silastic intrathoracic chimney or silo around the herniated tissue and suturing the edges of the chimney to the perimeter of the diaphragmatic defect. ${ }^{11}$ With continuing fetal growth, diaphragmatic size and thoracic volume increase relative to the silo volume thereby providing increased space for lung growth and the gradual (relative) reduction of the herniated liver. ${ }^{12}$

The aim of the study was to compare the effects of in utero silo and patch repair methods of $\mathrm{CDH}$ on the respiratory system compliance (CST,RS) measured in premature and full term lambs at birth. lungs by the herniated viscera has already pro-

\section{Methods}

TREATMENT GROUPS

Static respiratory system compliance was 
measured in two series of lambs - full term and premature - that had undergone either patch or silo repair of a surgically created diaphragmatic hernia. These lambs were compared with normal (unoperated) lambs and lambs in which the hernia was not corrected.

Seventy eight Merino Poll Dorset sheep were date bred for use in these experiments. A total of 55 lambs were taken to completion of the experimental protocols. Thirty two lambs were taken to near full term (145 days gestation) and 23 lambs were delivered prematurely (128 days). Fifteen lambs aborted or were stillborn prior to delivery, and eight lambs were removed from the study due to failure to retain the surgically induced defect or because of other technical failures. In one term (uncorrected) lamb the compliance could not be calculated because of technical problems.

Studies received ethical approval from the Women's and Children's Hospital animal ethics committee.

\section{SURGERY}

Full details of the surgical procedures for hernia creation and correction for both types of surgery are given elsewhere. ${ }^{81112}$ Briefly, following general anaesthesia, the fetal diaphragm was exposed. The diaphragmatic hernia was surgically created at 72-74 days gestation by incising the left hemidiaphragm from the mediastinum to the lateral chest wall. The intestine was gently pulled into the chest. The fetal body wall and the uterus were closed and amniotic fluid was replaced with warmed amniotic fluid and sodium lactate solution containing antibiotics. The ewe was given postoperative analgesia and antibiotics.

At 107-108 days the hernia was repaired by either the patch or silo repair methods. Both methods utilise 0.020 inch thick Dacronreinforced Silastic sheeting (Dow Corning No. 501-3). In the patch method, which is carried out through the abdomen, a flat Silastic sheet is cut to size and directly sutured into the defect from below after shifting herniated viscera into the abdomen. A further patch is placed in the abdominal wall. In the silo repair, which is carried out through a thoracic incision, the Silastic sheet is wrapped around the herniated viscera in situ and the silo of Silastic so formed is sutured at its base to the edge of the hernia. ${ }^{11}$

\section{RESPIRATORY SYSTEM MECHANICS}

Lambs were intubated before removal from the uterus and before the first breath with a $4 \mathrm{~mm}$ (premature group) or $5 \mathrm{~mm}$ (term group) cuffed endotracheal tube (Malincrockdt). After suctioning of the tube and trachea the lamb was ventilated using a Baby Bird ventilator. Inspiratory pressure was limited to $20 \mathrm{~cm} \mathrm{H}_{2} \mathrm{O}$ for all full term lambs and $10 \mathrm{~cm} \mathrm{H}_{2} \mathrm{O}$ for all premature lambs. A rectal temperature probe was inserted and body temperature maintained at $38^{\circ} \mathrm{C}$ with a heating pad. When necessary, additional barbiturate anaesthesia (intravenous Nembutal) was given. Body weight, crown- rump length, and other morphological measurements were recorded at time of death. Lambs were either killed by barbiturate overdose after ventilation for 30 minutes, or had already died on the ventilator (mean (SD) time to death was $28.3(4.5)$ minutes for term lambs and $21.3(6.9)$ minutes for premature lambs). The endotracheal tube opening was then attached to the pressure transducer and syringe system.

\section{COMPLIANCE MEASUREMENT}

Pressure at the mouth was measured with a differential pressure transducer (Validyne DP15-30). Volume change was achieved using a syringe attached via three-way taps to the endotracheal tube.

Measurements were recorded on a Gould 2400 chart recorder. A volume history was established by injection and withdrawal three times of the gas volume corresponding to the maximum pressure $\left(10 \mathrm{~cm} \mathrm{H}_{2} \mathrm{O}\right.$ for premature and $20 \mathrm{~cm} \mathrm{H}_{2} \mathrm{O}$ for full term) allowed for that lamb. The volume injected to reach the maximum inspiratory pressure was recorded and used as a measure of lung volume. All volume and pressure measures were taken during deflation from maximum pressure, and deflations were repeated to produce at least three similar pressure-volume curves per animal. Deflation from the maximum volume proceeded in five equal volume decrements - that is, to $80 \%$, $60 \%, 40 \%, 20 \%$, and $0 \%$ of maximum volume. The pressure associated with each volume reduction was measured after the pressure trace had maintained a plateau for 15 seconds to allow for stress relaxation. ${ }^{13}$ The time taken to reach this plateau was from 30 seconds to several minutes. All in situ compliance measurements were completed within 20-30 minutes of death. At the end of compliance testing the transducer zero and gain settings were rechecked. Compliance of the test apparatus alone was less than $0.0026 \mathrm{ml} / \mathrm{cm} \mathrm{H}_{2} \mathrm{O}(1 \mathrm{ml} /$ $\mathrm{cm} \mathrm{H}_{2} \mathrm{O}=9 \cdot 8 \times 10^{-5} \mathrm{l} / \mathrm{kPa}$ ). Before and after each pressure-volume profile the test apparatus was checked for leaks.

Compliance was calculated as the mean slope (linear regression) of the three pressure-volume curves, and curves were constructed after discarding the $100 \%$ and $0 \%$ pressure-volume points.

In both the term and premature series of lambs the raw compliance values were also "corrected" for the influence of (i.e. divided by) the individual body weight or length, or the individual lung wet weight, or the lung volume that produced the maximum allowed inspiratory pressure.

\section{MORPHOLOGY}

After completion of compliance measurements the lungs were removed and whole and left and right lungs weighed. Lamb length was measured as crown-rump length.

Data were analysed using SigmaStat (Jandel). 

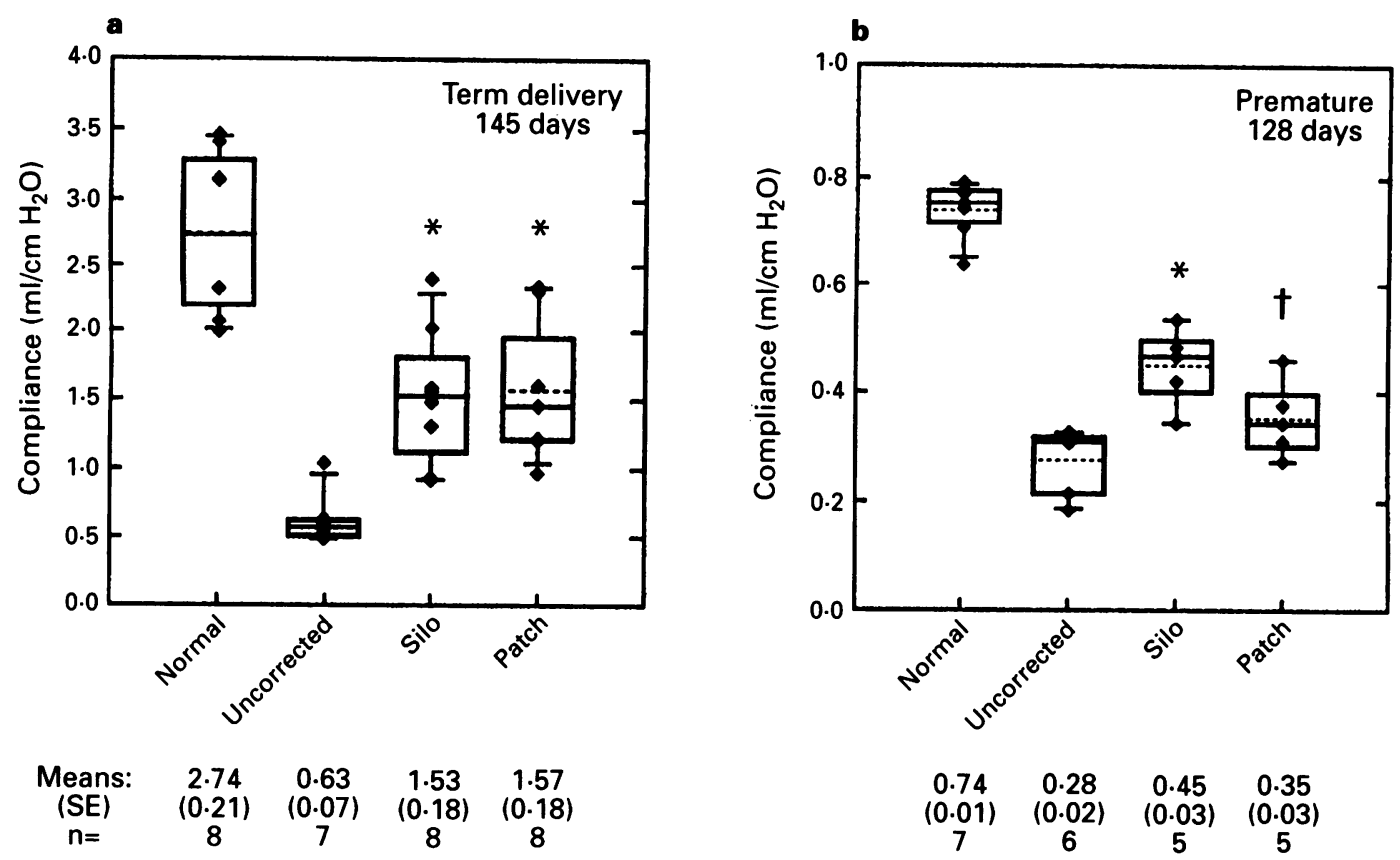

Static respiratory system compliance in (a) term and $(b)$ premature lambs. Box plot and data points displayed together. Box plot horizontals represent the $90 \%, 75 \%, 50 \%$, mean (dotted line-sometimes obscured) and $25 \%$ and $10 \%$ levels in the data distribution. Mean (SE) and number of lambs are also shown; * repaired group significantly different from the normal and uncorrected groups; $\dagger$ repaired group significantly different from the normal group and the silo group, but not different from the uncorrected group.

Comparisons between groups were made by one way ANOVA using the Student-NeumanKuhls procedure for multiple comparisons of groups. When parametric assumptions were not satisfied by the data the Kruskall-Wallis one way ANOVA was used with Dunn's test for multiple comparisons. The significance level was set at $\mathrm{p}<0.05$.

\section{Results}

The static respiratory system compliance (CST,RS) values for full term and premature lambs are summarised in the figure. At both gestations the mean compliance of the uncorrected lambs was significantly less than the mean value in normal lambs $(p<0.05)$. In both the term and premature lambs the silo correction produced a significant increase $(p<0.05)$ in mean compliance compared with uncorrected lambs. However, the mean CST,RS following patch correction was significantly greater than the mean value in uncorrected lambs only in the term lambs; in the premature series there was no difference to the uncorrected lambs.

There were no significant differences in mean lamb body weights or body lengths in the four groups of term lambs (table). Similarly, there were no significant differences in mean weights or lengths in the premature series of lambs (table). Therefore, when the raw CsT,RS values within either the term or premature series of lambs were "corrected" for the individual body weights or lengths there was no change in the relative compliance relationships between treatment groups - they remained as described above. In contrast, when CsT,RS was corrected for lung weight there were no statistical differences between any of the treatment groups and normal lambs within either the full term or the premature lamb series. Similarly, when corrected for the measure of lung gas volume, no differences in corrected mean compliance were apparent within either series.

\section{Discussion}

COMPARISON OF SILO AND PATCH REPAIR OF CDH This study has measured respiratory system compliance in 23 premature and 31 term lambs after repair of diaphragmatic hernia. It has demonstrated that in term lambs the improvements in respiratory system compliance provided by either repair method are comparable -

Group mean ( $S E$ ) values of static respiratory system compliance, body size, lung weight and volume for each treatment group in the term and premature series

\begin{tabular}{|c|c|c|c|c|c|c|c|c|}
\hline & \multicolumn{4}{|l|}{ Full term } & \multicolumn{4}{|l|}{ Premature } \\
\hline & $\begin{array}{l}\text { Normal } \\
(n=8)\end{array}$ & $\begin{array}{l}\text { Uncorrected } \\
(n=7)\end{array}$ & $\begin{array}{l}\text { Silo } \\
(n=8)\end{array}$ & $\begin{array}{l}\text { Patch } \\
(n=8)\end{array}$ & $\begin{array}{l}\text { Normal } \\
(n=7)\end{array}$ & $\begin{array}{l}\text { Uncorrected } \\
(n=6)\end{array}$ & $\begin{array}{l}\text { Silo } \\
(n=5)\end{array}$ & $\begin{array}{l}\text { Patch } \\
(n=5)\end{array}$ \\
\hline $\begin{array}{l}\text { Compliance }\left(\mathrm{ml} / \mathrm{cm} \mathrm{H}_{2} \mathrm{O}\right) \\
\text { Body weight }(\mathrm{kg}) \\
\text { Body length }(\mathrm{cm}) \\
\text { Lung weight }(\mathrm{g}) \\
\text { Lung volume }(\mathrm{ml})\end{array}$ & $\begin{array}{c}2 \cdot 74(0 \cdot 22) \\
4 \cdot 73(0 \cdot 31) \\
43 \cdot 8(0 \cdot 9) \\
257(16) \\
39.9(2 \cdot 8)\end{array}$ & $\begin{array}{l}0.63(0.07) \\
4.30(0.24) \\
42.4(0.5) \\
55(4) \\
8.2(0.7)\end{array}$ & $\begin{array}{c}1.53(0 \cdot 18) \\
4 \cdot 51(0 \cdot 19) \\
44 \cdot 0(0 \cdot 2) \\
130(5) \\
25 \cdot 1(3 \cdot 1)\end{array}$ & $\begin{array}{c}1.57(0 \cdot 18) \\
4 \cdot 68(0.08) \\
44.0(0 \cdot 4) \\
157(14) \\
20.5(2 \cdot 4)\end{array}$ & $\begin{array}{c}0 \cdot 74(0 \cdot 02) \\
2 \cdot 94(0 \cdot 11) \\
37 \cdot 7(0 \cdot 2) \\
116(12) \\
5 \cdot 1(0 \cdot 1)\end{array}$ & $\begin{array}{l}0.28(0.03) \\
3.05(0.27) \\
36.5(0.8) \\
38(5) \\
1.9(0.2)\end{array}$ & $\begin{array}{l}0.45(0.03) \\
2.99(0 \cdot 19) \\
38 \cdot 6(0 \cdot 5) \\
78(14) \\
2 \cdot 8(0 \cdot 1)\end{array}$ & $\begin{array}{l}0 \cdot 35(0 \cdot 03) \\
2 \cdot 88(0 \cdot 14) \\
37 \cdot 6(0 \cdot 9) \\
85(13) \\
2 \cdot 3(0 \cdot 2)\end{array}$ \\
\hline
\end{tabular}


that is, the CST,RS was significantly improved following in utero surgical repair of the hernia by either the silo or patch methods (figure, a). In premature lambs, however, the silo repair method resulted in significantly improved CST,RS values compared with the patch repair method (figure, b), suggesting that silo repair may confer an additional compliance advantage in those born prematurely.

POTENTIAL FETAL SURGERY: BENEFITS FOR CDH Because of the high mortality in infants born with $\mathrm{CDH}$, attention is now being focused on in utero repair as it is reasoned that earlier repair of the defect may improve lung development and subsequent progress. A repair technique commonly used is the patch technique, develped in lambs by Harrison et al. ${ }^{8}$ An alternative method (Ford et $a l^{12}$ ) is the silo repair which may be less complex and potentially reduces the risk of premature labour. In addition, the silo method has the potential of being used in those infants with herniated liver in the chest - a group with the worst prognosis. ${ }^{10}$ In the latter group the silo repair aims to avoid the acute kinking of the ductus venosus that is associated with the patch repair by allowing the gradual reduction of the herniated liver. ${ }^{1112}$ Nevertheless, this study was unable to specifically address the difficulties of correcting a hernia with a large volume of liver in the chest as only two lambs had herniated liver at the time of repair.

The study design aimed to compare directly the effects of the patch and silo methods of $\mathrm{CDH}$ repair on static respiratory system compliance to determine whether the silo method, with its gradual (relative) reduction in hernia size with fetal growth, was comparable in its respiratory effects to the patch method, especially as many of the human fetuses treated antenatally have been born prematurely.

\section{CHOICE OF INSPIRATORY PRESSURES}

Several considerations dictated the choice of $20 \mathrm{~cm} \mathrm{H} \mathrm{H}_{2} \mathrm{O}$ inspiratory pressures in term lambs and $10 \mathrm{~cm} \mathrm{H}_{2} \mathrm{O}$ in premature lambs. Kent $e a^{a l^{14}}$ reported lung compliance studies in eight term lambs with surgically created $\mathrm{CDH}$. Two lambs in that study died from pneumothorax when inflating pressures exceeded $30 \mathrm{~cm} \mathrm{H}_{2} \mathrm{O}$. In their series of term lambs with $\mathrm{CDH}$ deLuca et $a l^{15}$ reported a highly significant increase in pulmonary interstitial emphysema when higher transpulmonary pressures were used during ventilation. For these reasons the maximum inspiratory pressure was limited to $20 \mathrm{~cm} \mathrm{H}_{2} \mathrm{O}$ in term lambs. Because of the potentially greater risk of lung barotrauma in the premature lambs studied close to the time of surgical correction of their diaphragmatic hernia, inspiratory pressures in these lambs were limited to $10 \mathrm{~cm} \mathrm{H}_{2} \mathrm{O}$.

Limiting pressures in this way may have resulted in a degree of airway non-recruitment, leading to an underestimation of CST,RS. However, each of the treatment groups within the term and premature series received the same pressure limitation so that the relative differences between groups are likely to remain valid.

SPECIFIC COMPLIANCE: CORRECTIONS

Conventionally, "raw" compliance values are corrected to body or lung size to allow comparison between subjects of varying size. ${ }^{16}$ The parameters most commonly used for this purpose are body weight/length and functional residual capacity (FRC). ${ }^{17}$

In this study the correction of raw CST,RS values by body weight or length would not be expected to alter any differences found within the premature or term lamb series since within a series there were no statistical differences in lamb length or weight. Thus the raw CST,RS values were essentially divided by a constant, making this "correction" meaningless. This result is not surprising because the lungs are not a vital factor in body growth in utero.

In contrast, when the raw CST,RS values were "corrected" for lung weight or for the volume of the lung at maximum distending pressure (term: $20 \mathrm{~cm} \mathrm{H} \mathrm{H}_{2} \mathrm{O}$; premature: $10 \mathrm{~cm} \mathrm{H}_{2} \mathrm{O}$ ) no difference in the corrected CST,RS values was found between normal and uncorrected term or premature lambs or between uncorrected and silo or patch repaired lambs. This latter result suggests that the relative differences in raw CST,RS values observed between the normal, uncorrected, and repaired lambs in either the term or premature series are predominantly due to differing lung size rather than intrinsic differences in respiratory system compliance.

The contribution of hypoplastic areas of the lung to CST,RS is likely to be small. Measurement of CsT,RS is by the assessment of mouth pressure at differing lung volumes. Mouth pressure (in the absence of muscle contraction) reflects the total recoil pressure of those areas of lung whose airways are patent. The contribution of a hypoplastic poorly ventilated area to the total lung recoil pressure may therefore be overshadowed by the contribution of the patent "normal" areas.

COMPARISON OF VALUES OF RESPIRATORY SYSTEM COMPLIANCE WITH OTHER STUDIES

Davis et $a l^{18}$ have reported higher mean respiratory system compliance values in normal lambs $\left(1.97 \mathrm{ml} / \mathrm{cm} \mathrm{H} \mathrm{H}_{2} \mathrm{O} / \mathrm{kg}\right.$ ) than those found in this study $\left(0.58 \mathrm{ml} / \mathrm{cm} \mathrm{H}_{2} \mathrm{O} / \mathrm{kg}\right)$. In the former study, however, the lambs were alive and breathing spontaneously. In contrast, in this study pressure and volume changes were recorded after death. Wohl et al ${ }^{19}$ reported that, after death, the cessation of blood flow affects vascular bed turgidity. Smooth muscle and chest wall muscle tone will also be altered. ${ }^{19}$ Each of these factors could alter the pressure and volume values recorded. Glick et $a l^{2}$ recently reported mean uncorrected compliance values of $8 \mathrm{ml} / \mathrm{cm} \mathrm{H}_{2} \mathrm{O}$ in 10 excised lamb lungs immediately after death. The mean CST,RS values found in the study reported here are lower. Insufficient detail was given in the study by Glick $e t a l^{20}$ to allow determination of what 
factors might be responsible for this difference, and the chest wall compliance in newborns is small enough to have little bearing on the total respiratory system compliance. ${ }^{21}$ However, there appeared to be no volume history performed prior to the pressure-volume measurement. It also appears that lung compliance was measured during the first inflation-deflation manoeuvre after delivery, at which time compliance will be changing rapidly.

Whatever the reasons are for the different absolute compliance values between this study and previous studies, the clear respiratory system compliance differences found between the normal, uncorrected, and repaired lamb groups in our study remain.

\section{LIMITATIONS OF THE MODEL}

Although this sheep model of $\mathrm{CDH}$ mimics many of the aspects of $\mathrm{CDH}$ in the human infant, ${ }^{112223}$ clearly caution must be used in the rigid extrapolation of findings in animals to the human fetus. A surgically created hernia cannot replicate a naturally occurring one, one which is initiated at an earlier stage of fetal and lung development. $^{24}$ This is especially true in the more severe forms of $\mathrm{CDH}$ which also involve defects in other organs - for example, heart, vertebrae, vasculature.

The lamb model of $\mathrm{CDH}$ does, however, have merit for developing surgical repair techniques. In normal human lung development the gut returns to the abdominal cavity in the tenth week - this is in the pseudoglandular phase and is when herniation can occur. In lambs the timing of lung development is different; the pseudoglandular phase extends to 85-90 days ${ }^{23}$ - that is, $60 \%$ of gestation. Surgically created diaphragmatic hernias in lambs at 72-74 days gestation are therefore comparable to the human neonate at 10 weeks with regard to the lung developmental stage. Pringle ${ }^{23}$ has reported that, at birth, the lungs of both lamb and human neonates with $\mathrm{CDH}$ are at the saccular stage and so the developmental stages are again comparable.

This study was supported by grants from the AMCWC Research Foundation. Thanks are due to $C$ Stewart and $T$ Hannant for assistance with data analysis.

1 Puri P. Epidemiology of congenital diaphragmatic hernia. In: Puri P, ed. Congenital diaphragmatic hernia. Mod Probl Paediatr 1989;24:22-7.

2 Adzick NS, Harrison MR, Glick PL, Nakayama DK, Man- ning FA, de Lorimier AA. Diaphragmatic hernia in the fetus: prenatal diagnosis and outcome in 94 cases. 7 Pediatr Surg 1985;20:357-61.

3 Adzick NS, Vacanti JP, Lillehei CW, O'Rourke PP, Crone RK, Wilson JM. Fetal diaphragmatic hernia: ultrasound diagnosis and clinical outcome in 38 cases. $\mathcal{f}$ Pediatr Surg 1989;24:654-8.

4 Harrison MR, Adzick NS, Flake AW, Jennings-RW, EstesJM, MacGillivray-TE, et al. Correction of congenital diaphragmatic hernia in utero: VI. Hard-earned lessons. $\mathcal{J}$ Pediatr Surg 1993;28:1411-8.

5 Sakai H, Tamura M, Hosokawa Y, Bryan AC, Barker GA, Bohn DJ. Effect of surgical repair on respiratory mechanics in congenital diaphragmatic hernia. $f$ Pediatr in congenital

6 Nakayama DK, Motoyama EK, Tagge E. Effect of preoperative stabilisation on respiratory system compliance and outcome in newborn infants with congenital diaphragmatic hernia. $\mathcal{F}$ Pediatr Surg 1991;118:793-9.

7 Charlton AJ, Bruce J, Daveport M. Timing of surgery in congenital diaphragmatic hernia. Anaesthesia 1991;46: 820-3.

8 Harrison MR, Adzick NS, Longaker MT, Goldberg JD, Rosen MA, Filly RA, et al. Successful repair in utero of a fetal diaphragmatic hernia after removal of herniated viscera from the left thorax. N Engl ₹ Med 1990;322:1582-94.

9 Harrison MR, Adzick NS, Flake AW, Jennings RW. The CDH two-step: a dance of necessity. F Pediatr Surg 1993; 28:813-6.

10 Pringle KC. Fetal surgery: practical considerations and current status: where do we go from here with Bochdalek diaphragmatic hernia? In: Fallis JC, Filler RM, Lemoine $\mathrm{G}$, eds, Pediatric thoracic surgery. Current topics in general thoracic surgery. New York: Elsevier, 1991:333-43.

11 Ford WDA, Cool J, Derham R. Intrathoracic silo for the potential antenatal repair of diaphragmatic herniae with potential antenatal repair of diaphragmatic hernia
liver in the chest. Fetal Diagn Ther 1992;7:75-81.

12 Ford WDA, Martin AJ, Cool J, Parsons DW, Kennedy JD. Intrathoracic silo for fetal diaphragmatic hernia: lung growth and slow reduction of abdominal viscera. $\mathcal{f}$ Pediatr Surg 1993;28:1006-8.

13 Dawson A. Elastic recoil and compliance. In Clausen JL, Zarins LP, eds Pulmonary function testing guidelines and controversies. New York: Academic Press, 1982:193-204.

14 Kent GM, Olley PM, Creighton RE, Dobbison T, Bryan $\mathrm{MH}$, Symchych $\mathrm{P}$, et al. Hemodynamic and pulmonary changes following surgical creation of a diaphragmatic changes following surgical creation of a diaphr
hernia in fetal lambs. Surgery 1972;72:427-33.

15 deLuca U, Cloutier R, Laberge JM, Fournier L, Prendt H, Major $\mathrm{D}$, et al. Pulmonary barotrauma in congenital diaphragmatic hernia: experimental study in lambs. $\mathcal{f}$ Pediatr Surg 1987;22:311-6.

16 England SJ. Current techniques for assessing pulmonary function in the newborn and infant. Pediatr Pulmonol 1988;4:48-53.

17 American Thoracic Society and the European Respiratory pociety (ATS-ERS). Respiratory mechanics in infants: physiologic evaluation in health and disease. Official state-
ment of the American Thoracic Society and the European ment of the American Thoracic Society and the Europe

18 Davis GM, Coates AL, Dalle D, Bureau MA. Measurement of pulmonary mechanics in the newborn lamb: a comparison of three techniques. F Appl Physiol 1988;64:972-81.

19 Wohl MEB, Turner J, Mead J. Static volume-pressure curves of dog lungs - in vivo and in vitro. $\mathcal{f}$ Appl Physiol 1968;24:348-54.

20 Glick PL, Stannard VA, Leach CL, Rossman J, Hosada Y, Morin FC, et al. Pathophysiology of congenital diaphragmatic hernia II: the fetal lamb CDH model is surfactant deficient. F Pediatr Surg 1992;72:382-8.

21 Mortola JP, Saetta M. Measurements of respiratory mechanics in the newborn: a simple approach. Pediatr Pulmonol 1987;3:123-30.

22 De Lorimier AA, Tierney OF, Parker HR. Hypoplastic lungs in fetal lambs with surgically congenital diaphragmatic hernia. Surgery 1967;62:12-8.

23 Pringle KC. Lung development in congenital diaphragmatic hernia. In: Puri P, ed. Congenital diaphragmatic hernia. Mod Probl Paediatr 1989;24:28-53.

24 Iritani I. Experimental study on embryogenesis of congenital diaphragmatic hernia. Anat Embryol 1984;169:133-9. 